\title{
Chapter 10 \\ Green City: Towards Low-Carbon \\ Urban Planning and Governance
}

\begin{abstract}
Green city is a development concept that has been widely embraced by the international community, especially by metropolises. In a broad sense, "green" indicates a city's overall habitability, in terms of environmental health (pollution prevention and control, carbon emissions, and air quality), public space design (environmental aesthetics and a city's vitality), equality of the social resource distribution (housing supply and wealth inequality), transportation efficiency (green commuting), and sustainability of energy consumption (efficient use of renewable energy sources). China is facing a series of issues as it heads towards its green city vision. From the perspective of spatial planning, we believe high carbon emissions are fundamentally resulted from outdated construction methods due to inefficient land use and housing supply-demand mismatch, and long commutes for workers caused by the separation of residence from workplace. From the perspective of technologies used in the construction and maintenance of transportation facilities, we believe that the penetration of alternative-fuel vehicles (AFV) in public transport remains low, and the lack of profitability of urban rail transit is a problem that should be urgently addressed. New technologies and techniques are needed to reduce energy consumption and carbon emissions from the production of building materials and the construction and operation of buildings. The use of aging water and heat supply facilities leads to high loss rates. Meanwhile, China's resource recovery sector is still in its infancy, and the reliance on human labor to offer services such as waste sorting points to room for operating efficiency enhancement. This chapter discusses the goal of building green cities in the context of carbon neutrality, outlines possible policies and measures to address the above-mentioned issues, and quantifies the carbon emission reduction achieved by optimizing systems for urban planning and housing supply, and adopting new technologies.
\end{abstract}

\subsection{Problems and Challenges Facing China in Its Green City Vision}

Globally, cities such as Vancouver, Melbourne, Toronto, Copenhagen, and Rotterdam have made remarkable progress in their green city development, especially in terms 
of energy conservation, emission reduction, and the overall consideration of environmental issues during the urban planning process. Several factors have contributed to their success, including the early adoption of sustainable development visions, the effectiveness of their environmental policies, and their improving industrial structures. Cities with stronger industrial vitality such as London, Paris, New York, Tokyo and Singapore are also taking the lead in green city development, which represents an important component of a city's "soft power". We have noticed many similarities between these cities: (1) preliminary urban planning (comprehensive urban planning focusing on sustainability in the long term, corresponding with long-term development goals, and adopting to extensive public feedback); (2) widespread support among the public; (3) continuity and integration of macro policy and city planning regulations; and (4) establishment of effective supervision mechanisms.

Green technologies utilized in urban planning are mainly related to transportation, municipal facilities, ecological land use, and construction engineering. We believe the experience from other countries is instructive for China, and will help China address problems of its emerging "urban diseases". Furthermore, the development of livable cities with more environmental-friendly facilities and a more sustainable atmosphere fundamentally echoes the pursuit of la dolce vita for Chinese people.

Two major challenges confronting China in its process towards green cities are improving the overall spacial structure of cities and promoting the technological developing in related fields. Nowadays, most urban planning for major Chinese cities still fits into the "monocentric city" framework, which has caused the following issues:

1. Inefficient urban land use-e.g. inefficient use of industrial land, the separation of residence from workplace, and the mismatch between housing supply and demand.

2. Inefficient transportation system. The overall transportation planning efficiency as well as the coverage and accessibility of public transport facilities still need improvement.

3. Insufficient construction technology improvement and lack of management methods for existing building. At present, building management and maintenance in China consumes high quantities of energy and generates heavy pollution, especially a large volume of carbon emissions in the process of building materials production and the building construction. The standard for the management of buildings throughout their life cycles is not yet in place.

4. Inefficient city operation and maintenance. The idea of environmental protection and sustainable development has been more widely promoted in China in recent years, but problems remain in fields such as water/heat supply, resource recycling, and waste sorting.

We believe that several factors including spatial arrangements, formulation of policies and regulations, technology application, standard setting, and public participation in city planning should be better coordinated in order to address the above problems. Given the increasingly strict control over new land quotas for building 


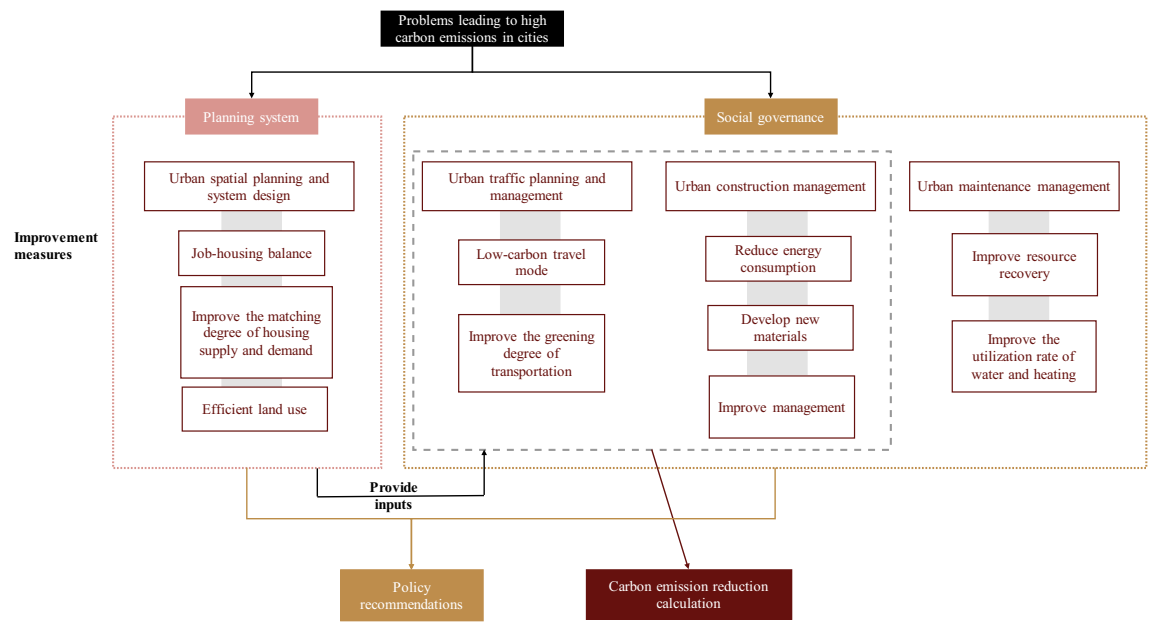

Fig. 10.1 Structure of this chapter. Source CICC Research

construction, we believe China needs to find a balance between expectations and realities to achieve its sustainable urban development goals.

In order to achieve the green city vision, we believe future urban planning should be based on: (1) the current development stage of the industrial economy, and the environmental governance goal; (2) coordination between the industrial development and infrastructure construction; and (3) optimization of spatial arrangements and management skills of urban development. This chapter discusses possible solutions to the abovementioned problems from four perfectives: (1) urban spatial planning (addressing issues such as inefficient land use, separation of the residence from workplace, and housing supply-demand mismatch); (2) urban transportation planning (promoting low-carbon commuting); (3) urban construction management (addressing the issue of using energy-consuming construction technologies and environmentally harmful building materials as well as improving the management of existing buildings): and (4) urban maintenance and management (promoting efficient water usage and waste recycling). See Fig. 10.1 for the structure of this chapter.

\subsection{Urban Spatial Planning: Building Cities with Sufficient Housing Supply and Evenly Distributing Residences and Workplaces}

Cities are major sources of carbon emissions, which are mainly generated by following 3 factors: (1) residents' reliance on private cars for long-distance commuting due to the spatial separation between residence and workplace as well 
as the uneven distribution of urban resources (e.g., restaurants, entertainment facilities, supermarkets and hospitals); (2) the mismatch between housing supply and demand; and (3) low-density construction in built-up areas. This chapter discusses possible countermeasures from the perspectives of urban spatial planning and institutional design, and suggests methods for calculating carbon emissions reduction in following sections.

\subsubsection{Evenly Distributing City Resources to Reduce Commuting Distances}

Developing multiple business centers and creating 15-min community life circles. The majority of mature and emerging cities in China are suffering from "urban disease" as a result of the monocentric city model. Due to the concentration of urban resources in a single core area, residents living in the suburbs have to suffer long commutes to work. The cost of long-distance commuting increases the value of residences and living space in the core area which increase market prices of these residences and forcing some people to move to the suburbs. This further exacerbates the uneven distribution of urban resources leading to high carbon emissions and low traffic efficiency. In order to reduce urban carbon emissions by shortening the average commuting distance, we believe it is important to create multiple business centers and 15-min community life circles.

Switching from the single-core to the multi-core city model. The even and fair redistribution of urban resources in a city is the key to addressing the issue of spatial separations between living and working areas, and it can eventually leads to shorter commutes. We believe that the following should be considered in future urban planning:

- Promoting multi-core city model development and improving the rapid transit system. We believe developing subcenters based on traffic locations, industrial bases, and economic connections between city cores is more likely to bring capital to high-quality industries which can boost economic growth in the short- and medium-term. On the other hand, a rail transit network is important for a city's sustainable development. Rail transit network needs to be extended to suburbs to strengthen economic linkages between urban centers and subcenters. Inter-city rapid transit systems should also be encouraged between major cities such as Beijing and Shanghai to strengthen economic interconnectivity with surrounding satellite cities.

- Encouraging mixed-use urban planning ideas. We believe large- and mediumsized cities should focus more on urban planning in order to unleash potential of the limited land resources. While ensuring land resources for different uses are reasonably allocated, we believe governments should consider adding more functions to the previous single-purposed lands during the planning process. On the other hand, government should pay more attention to "fill-in" the structures of existing 
construction land and to revitalize these areas by renovating and upgrading old residential communities, factories, commercial buildings, and other supporting facilities.

Building 15-min community-life circles by better allocating basic service facilities. Reasonable allocation of urban resources surrounding the residential area is important to build 15-min community-life circles that can fulfill the residents' needs for consumption, entertainment and social life. Two issues should be considered when building 15-min community-life circles:

- Efficient combination of facilities for walking, cycling and public transport. Cities should provide transportation facilities based on walking distance so that residents have various options to reach their destinations (walking, cycling and public transport) within a 15-min community-life circle. The availability of transport options will help reduce the use of private cars to reduce traffic jams during rush hours. Moreover, during urban planning and designing, it is necessary to construct supplementary facilities in residential areas to satisfy basic service needs of residents. The locations of these service facilities should be selected based on the principle of covering wider range of residents and areas.

- Compact and diversified arrangement of business structures. Under the transit-oriented development (TOD) model, properties within the 15-min life circle needs to be compactly arranged to include all the necessary resources for various daily life scenarios (e.g. residence, shopping, medical care, entertainment, and socializing). This compactness is not only reflected in the compression of distance and efficient use of space, but also in the diversification of services provided. Urban planners also need to consider the varying demand for daily services across different income groups.

Taking the above-mentioned urban planning strategy as the future adjustment path, we calculate the possible reduction of urban commuting distance in some major cities in China, and use the result as a basis to calculate the carbon emission reduction in urban traffic management segment. Assuming residence and workplace are evenly distributed in 36 selected major cities, we estimate that the average commuting distance will decrease to $115.3 \mathrm{bn} \mathrm{km}$ (adjusted to $83.7 \mathrm{bn} \mathrm{km}$ after considering some uncontrollable factors in urban planning).

From the perspective of urban planning, there are two types of commutes: (1) Commutes caused by the separation between residential areas and the workplace. Excluding individual preferences for employment and the location of residences, we assume that if everyone worked as close to home as possible, it would minimize the average commuting distance. According to data from China Academy of Urban Planning and Design (CAUPD), we estimate that 30-60\% of the commuting distances are caused by the separation of residence from workplace (Fig. 10.2). (2) Extra distance caused by the discrepancy between individual preferences for the location of workplaces and residences.

International urban planning scholars have noted that a reasonable commuting distance for walking and biking is 1-2 miles (1.6-3.2 km). Although cities have been profoundly changed by economic development and technological advances, 


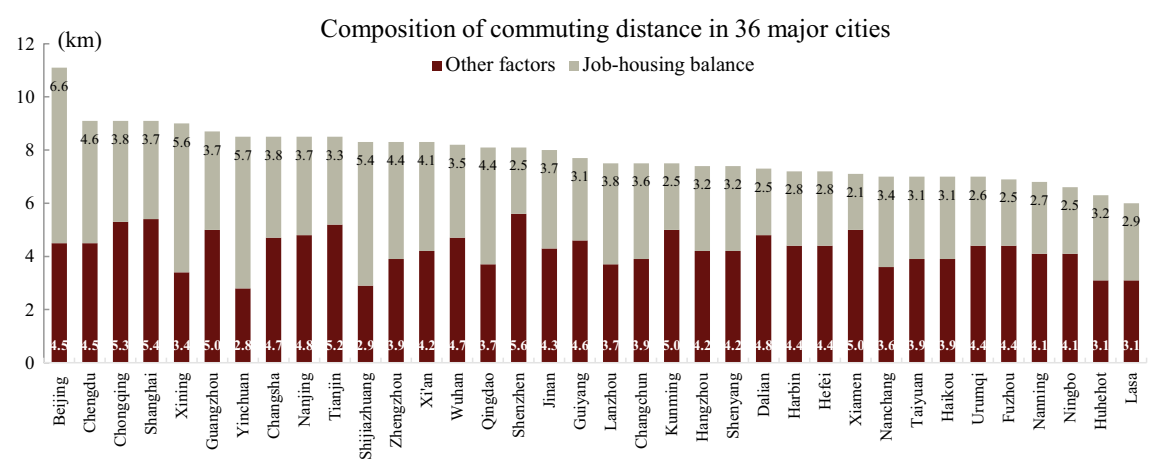

Fig. 10.2 We estimate that $30-60 \%$ of the commuting distances in 36 major cities are caused by the separation of residence from workplace. Source 2020 Monitoring Report on Commuting in Major Cities by CAUPD, CICC Research

we believe the commuting distance proposed by the scholars remains valid today. We believe measures, such as building multi-centric cities and 15-min life circles, can help reduce the commuting distance to the suggested range, and we can calculate the decline of commuting distance for each employee when the residence and workplace are evenly distributed from the perspective of urban planning. Nearly $70 \%$ of the Chinese population worked in cities at end-2019, of which our calculation of commuting population in 36 select cities is based. We estimate that the even distribution of residence and workplace can reduce total commuting distance in these cities by around $115.3 \mathrm{bn} \mathrm{km}$ per year. Considering the difficulty of urban planning adjustments varies for cities at different development stages, we classify cities into super-large, extra-large, large and medium-sized based on population size and average commuting distance, and set breakage coefficients based on the difficulty of urban planning changes. Factoring in the difficulty of urban planning adjustments, we estimate the total commuting distance in major cities would be reduced to $83.7 \mathrm{bn}$ $\mathrm{km}$ per year.

\subsubsection{Designing a Reasonable Housing System, and Matching Housing Supply with Demand to Reduce Carbon Emissions}

China's housing supply is sufficient though the distribution of housing supply still has structural problems. China had around 30bn sqm in housing inventory in urban areas at end-2019, and the ratio between number of inventory housing and households (1.1/household) was already on par with that in overseas mature housing markets. However, structural problems remain to be solved: (1) Uneven geographical distribution. Judging by the permanent resident population, we believe the residential land 
supply is insufficient in ultra-high-tier and high-tier cities (classified by CICC real estate team). (2) Uneven distribution among different income groups. According to a survey by the National Bureau of Statistics (NBS), nearly 15\% of urban households faced housing difficulties in 2015, and the proportion was over $25 \%$ in developed cities such as Beijing and Shanghai. Meanwhile, the lowest-income urban residents (20\%) only occupied $6 \%$ of housing resources.

Housing construction is a major source of urban carbon emissions. We explore possible improvement of system design (from the perspective of housing supply, land market and taxation system) to address the housing supply-demand mismatch.

\subsubsection{Housing Supply System: Focusing on Commercial and Government-Subsidized Housing}

Government-subsidized housing programs satisfy the basic housing needs of $\mathrm{mid} /$ low-income households, helps build a multi-layer housing supply system, and reduce invalid housing supply. We believe the existing housing supply system can be improved in the following aspects:

- Catering to the housing needs of neglected groups. China's subsidized housing program has long neglected college graduates and professional employees. We believe maintaining a reasonable ratio between the supply of subsidized housing for professional employees and general subsidized housing (e.g. 7:3 in Shenzhen) can meet the basic housing needs of college graduates and professional employees.

- Designing a suitable investment and financing system to encourage governments and the private sector to participate in subsidized housing projects. The long investment recovery period and ineffective exit mechanism are major reasons hindering the acceleration of subsidized housing construction. We believe designing a suitable investment and financing system is the key to encouraging local governments and the private sector to participate in subsidized housing projects, such as increasingly land supply and using REITs (real estate investment trusts). At the same time, financial and fiscal measures could further encourage non-stateowned companies to participate in the construction of affordable housing, while expanding the coverage of policy-based housing should increase the return on REITs and enhance the feasibility of their exit mechanism.

- Balancing subsidized housing construction among different cities and districts. Land sales data over 2009-2019 suggests that more subsidized housing projects were built in medium/low-tier cities, and we believe supply of public rental housing in ultra-high and high-tier cities should be increased. Moreover, building subsidized housing and supporting infrastructure facilities where public transport is accessible should fulfill the demand from middle-to-low income households, and reduce the vacancy rate of subsidized housing. Meanwhile, extensive housing construction in one single region should be avoided to prevent social tension caused by residential isolation. 


\subsubsection{Deepening Land Market Reform}

Land market reform is the prerequisite and foundation for building a multi-layered housing supply system. We believe that most supply-side issues in domestic real estate market can be traced back to the low efficiency of land supply. Under the existing institutional framework, we believe the land market reform should be deepened in the following aspects:

- Improving national system for the trading of construction land quotas. Academic studies generally accept that the inefficiency of national construction land quota system is the key reason for the uneven distribution of land supply. Provincial land quota trading systems are relatively mature, and cross-province trading of unused land quotas has been successfully trialed. We believe the national land quota trading system should be improved in the following aspects: (1) delegating of trading rights from provinces to counties and cities; (2) supplementing innerprovincial trading rights with inter-provincial trading; and (3) making information more transparent and distributing benefits fairly.

- Building unified construction land markets for urban and rural areas. In order to develop a unified land supply market for urban and rural areas, we believe: (1) construction land in all area should be equally considered in urban planning; (2) a unified benchmark land price system should be built and land transaction prices should be disclosed (market competition will drive land prices in rural and urban areas towards a similar outcome); and (3) a reasonable profit distribution system should be built to avoid assigning too much social responsibilities on collective land owners.

\subsubsection{Fiscal and Taxation Systems: Introducing Fair and Reasonable Property Taxes}

We believe the introduction of a fair and reasonable housing property tax will: (1) better motivate local governments to advance land market reform; and (2) curb speculative housing investment and facilitate income redistribution. We believe that the housing property tax should take these two issues into consideration:

- Clarifying the purpose of levying housing property tax. We believe property tax should remain stable over the long term, which differs from the flexibility and timeliness of regulatory measures. Judging by the experience in overseas housing markets, we do not believe that property taxes alone can sufficiently curb housing price hikes and speculation. On the contrary, the property tax is a stable fiscal revenue source (over $20 \%$ in developed countries) due to its stability, transparency, and counter-cyclicality. Overall, we believe a combination of property tax and vacancy tax (as charged in France and Canada) will propel home owners to sell or rent, and curb housing speculation.

- Implementing property tax in two steps; promoting supporting systems. Both the land transfer fee and property tax are related to home ownership, and this may 
result in duplicate charges. However, we think the legal basis of property tax can be established by replacing lease renewal with sustainable land use after the period of residential land use expires, and adopting a low-rate and narrow-base property tax before the use period expires. We believe these measures would ensure that fairness is maintained, common housing demand is protected, and wealth effect in property market is regulated.

- By comparing the demand matching model and the current extensive reconstruction model, we estimate that the demand matching model will reduce the construction area by $21.2 \mathrm{bn}$ sqm in the next 40 years.

- Estimated new construction area in next 40 years under current "extensive demolition and reconstruction" model: Urban population is calculated based on population forecasts from the United Nations and the assumption that the China achieves its urbanization goal of $80 \%$ in 2050 . New construction area per urban resident is calculated based on the correlation between urbanization rate and per capita new construction area. By multiplying the urban population and new construction area per urban resident, we estimate total new construction area in urban area at 65.1bn sqm over 2021-2060 (Fig. 10.3).

- Estimated new construction area in the next 40 years under the "supply-demand matching" model: We calculate reasonable demand for residential area in the next 40 years based on our estimate on the reasonable demand for houses over the medium-to-long term, and the assumption that per capita residential area will increase. We assume housing projects account for nearly $72 \%$ of total new construction area, which estimates total new construction area in urban area at 43.9bn sqm over 2021-2060.

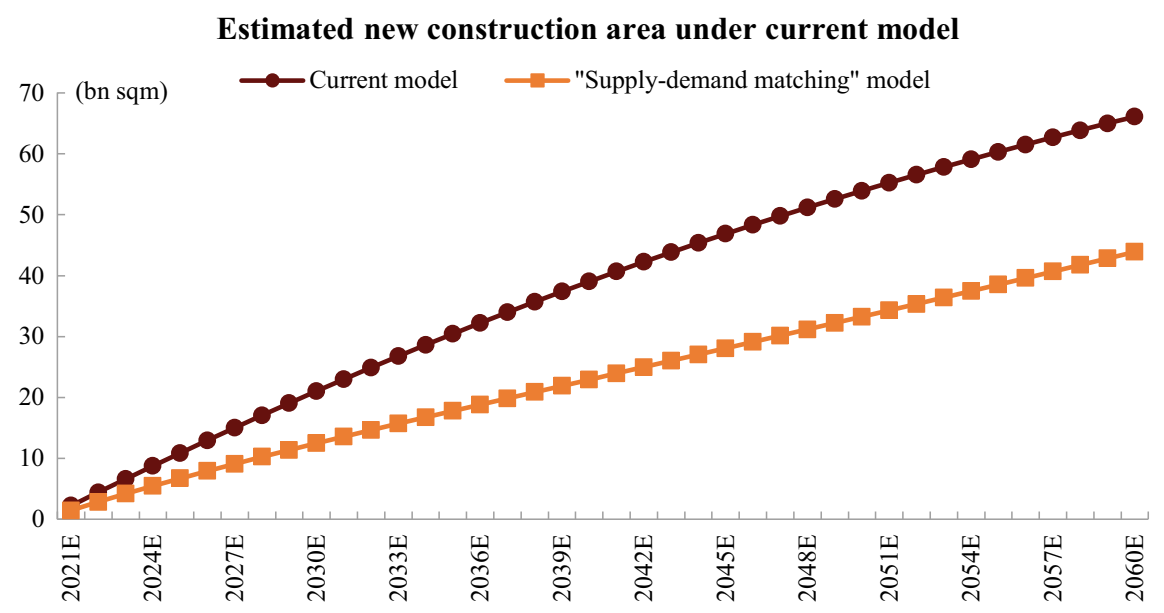

Fig. 10.3 Estimated new construction area under current "extensive demolition and reconstruction" model, and under "supply-demand matching" model. Source United Nations, National Bureau of Statistics, CICC Research 


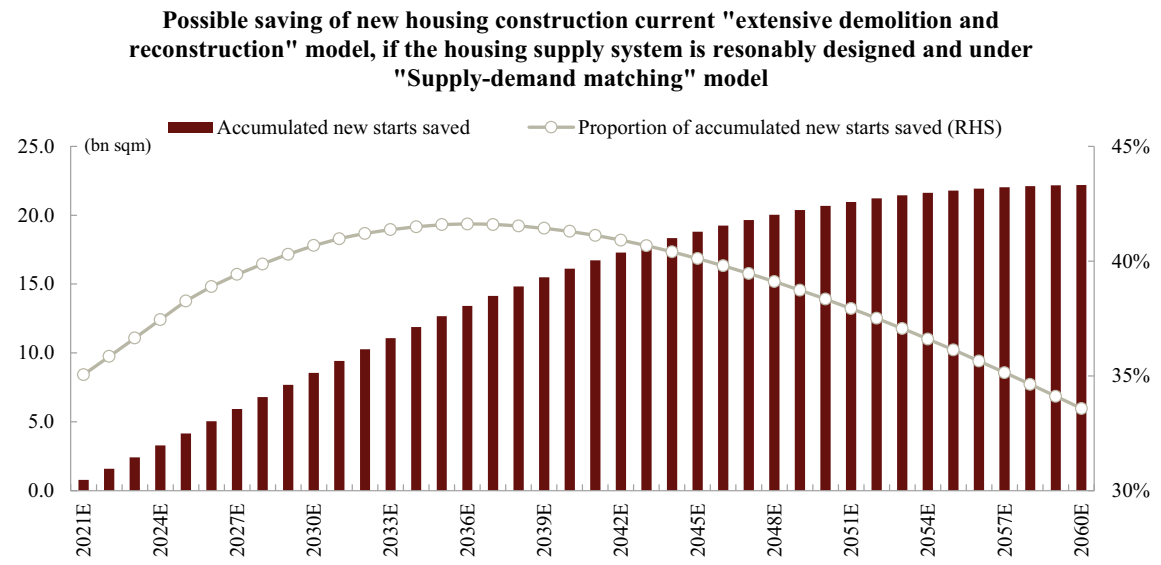

Fig. 10.4 Possible saving of new housing construction if the housing supply system is reasonably designed. Source United Nations, National Bureau of Statistics, CICC Research

- The difference of new construction area under two housing supply models is a redeeming feature of new housing construction. If China switches from current "extensive demolition and reconstruction" model to "supply-demand matching" model, we estimate new construction area in urban areas will drop $21.2 \mathrm{bn}$ sqm by 2060, equivalent to $33 \%$ of total new starts under the current model (Fig. 10.4).

\subsubsection{Using Land Efficiently to promote High-Quality Growth}

Low-efficiency and low-quality land use has led to high carbon emissions in cities. Under the conventional resource-driven development model, cities mainly rely on the input of production factors to enhance economic output. Most municipal governments have extensively developed land to attract rural migrants during the progress of urbanization, and the construction of large volumes of low-utilization supporting facilities pushed up overall carbon emissions. Average economic density in built-up areas of prefecture-level cities was around Rmb1,200/sqm by the end-2019, and there is plenty of room for improvement in all regions except for major city clusters in eastern China. We believe that improving city-industry integration and urban resilience is important for improving land use efficiency and reducing carbon emissions. 


\subsubsection{Improving City-Industry Integration; Exploring Development Axes}

Regional centers and satellite cities within major city clusters in mid-west China are the main destination for the migration of people and industries from the more economically-developed eastern coastal regions. Such cities are focused on turning a large population into a driver of economic growth by using land more efficiently. The following two issues should be addressed:

- City-industry integration. We believe high-quality urban expansion can be achieved by setting up economic and technological development zones and hightech industrial parks on the fringes of main urban areas and attracting highquality industrial projects with tax reductions and exemptions as well as low land costs. For example, the Zhengzhou municipal government built a modern service industry system in the Zhengdong New Area by introducing industry leading, competitive and large-size companies, creating a new growth driver for Zhengzhou's economy. We believe building infrastructure and developing service industries are important for new districts to reduce the reliance on urban centers.

- Development axis: Central urban areas — urban fringes - new urban areas — crossborder functional areas. Major cities such as Zhengzhou and Chengdu all have developed central urban areas and new urban areas, but the economic density still needs to improve in regions located between the main and new urban areas and in regions within the one-hour urban living circle. Economic links between different areas should also be strengthened. The function of urban fringes depends on the degree of separation between residential and workplaces in central urban areas. Fringe areas will mainly be used as residential areas when there is a lack in central urban housing. Otherwise, urban fringes will be used to develop employment subcenters to enhance economic density in between the central and new urban areas.

\subsubsection{Voluntarily Downsizing to Strengthen Urban Resilience}

Population density declined in nearly 80 cities in mid-western and northeastern China over 2010-2019, and population migration and relocation of companies to other regions were major reasons. As inefficient land use in these shrinking cities may cause more serious consequences, we believe the following measures should be taken:

- Promoting industrial transformation. In response to the stagnation of local traditional industries, we believe governments should develop new industries to meet local conditions. For example, the Yumen municipal government switched development focus from oil resources to tourism and organic agriculture after local oilfields were exhausted.

- Strengthening urban resilience. Urban functions in sparsely populated cities should be restored by building ecological networks on idle land, and public 
service facilities in city centers or commercial districts. This will strengthen urban resilience of these cities and prevent further population declines.

- Adopting proactive downsizing strategy. The bulk of domestic cities have yet to see serious downsizing, but we believe that cities should be forward-looking when urban planning. In cities that rely on traditional industries and lack natural resources, supply of land for traditional industries should be reduced, and inefficiently-used land in built-up areas should be readjusted.

\subsection{Urban Transportation: Wider Use of AFVs to Reduce Carbon Emissions from Urban Transportation}

This section discusses the potential reduction of carbon emissions in the urban transportation sector via measures such as increasing the use of alternative-fuel vehicles (AFV) in public transport, optimizing the urban railways, improving bike-sharing systems, and shortening average commutes. We believe that all buses, taxis and ride-hailing vehicles will be electric by 2030 , and that more passengers may choose low-carbon modes of transportation such as urban rail transit and bike sharing.

Transportation methods in cities mainly include rail transit, buses, taxis, ridehailing services, and bike sharing. Total urban passenger volume in China reached 165.6bn in 2019, of which buses, taxis, urban rail transit, ride-hailing platforms, and bike sharing accounted for $21 \%, 42 \%, 14 \%, 12 \%$, and $10 \%$, respectively. The proportion of taxis and buses declined compared to 2010, while the proportion of urban rail transit, ride-hailing platforms, and bike sharing increased 9\%, 12\% and $10 \%$, respectively, contributing to the progress of building low-carbon transportation system.

Taxis, buses, and ride-hailing services are the main sources of carbon emissions from urban transportation (excl. ride-hailing as it is classed among passenger vehicles in Chap. 8). We estimate carbon emissions in China from taxis and buses in 2019 totaled $31.32 \mathrm{mnt}$, with $24 \%$ from buses and $76 \%$ from taxis. We expect urban passenger volume to maintain annualized growth rate of 3-4\% (daily passenger volume in the US grew at a CAGR of $3.0 \%$ as per capita GDP increased from US\$13,000 to US\$36,000). We do not believe that carbon neutrality for urban transportation has only one solution as we think it can be achieved via the following measures: (1) gradually increasing the use of electric buses, electric taxis, and electric vehicles for ride-hailing services; (2) promoting low-carbon transportation such as urban rail transit and bike sharing before the electrification of public transport is complete. The urban rail transit and bike-sharing segments are facing different issues, which will be discussed in the following sections. 


\subsubsection{Electrification of Urban Buses, Taxis, and Ride-Hailing Vehicles to Complete in 2030}

The Innovation Center for Energy and Transportation (ICET) proposes in its report of Research on the Timetable for the Exit of Gasoline-fueled Vehicles in China (the "timetable research report") that taxis, ride-hailing cars, and buses should be among the first to complete electrification (gradual expansion from ultra-large cities such as Beijing, Shanghai and Shenzhen to other cities such as Tianjin, Hangzhou and Guangzhou).

- $59 \%$ of buses were electric in 2019, and the proportion may reach $100 \%$ in 2025. Data from the Ministry of Communications shows that China had nearly $0.41 \mathrm{mn}$ electric buses in 2019, accounting for 59\% of total buses in the country, and $90 \%$ of buses sold in 2018 were electric. We expect the electrification of buses to reach $100 \%$ in 2025.

- Electrification of taxis and ride-hailing cars will be completed before 2030. According to the Study on China's Timetable for Phasing-out Traditional ICEvehicles, gasoline-fueled taxis and gasoline-fueled cars for ride-hailing services will be gradually replaced by electric vehicles over 2020-2030.

Led by the government, taxis and ride-hailing cars may be first to achieve electrification. For example, the Shenzhen municipal government issued a blue-sky sustainable action plan in April 2018, and the electrification rate had reached 99\% for taxis and $100 \%$ for buses as of 2019. The electrification of government cars, public vehicles, and buses can be achieved by governments restricting purchases of gasolinepowered vehicles. We expect the electrification of urban buses, taxis, and ride-hailing vehicles to complete in 2030, realizing zero carbon emission.

\subsubsection{Switching to Low-Carbon Modes of Transportation Before 2030}

We expect increased use of low-carbon transportation modes such as urban rail transit, bike sharing, and walking before 2030, mainly considering: (1) urban rail transit will transport more passengers as the model of financing and profitability matures; (2) governments will collaborate with enterprises to enhance the efficiency of bike-sharing services; and (3) residents will likely be able to walk and bike to their workplaces thanks to the shortened commuting distance. 


\subsubsection{Increased Use of Urban Rail Transit to Reduce Carbon Emissions from Urban Transportation}

Density of urban rail transit in China remains lower than in developed countries. Among the world's ten largest cities measured by the operating mileage of urban rail transit, three are from China (Beijing, Shanghai and Guangzhou). However, the density of urban rail transit (as measured by the urban rail transit length per unit area) remains significantly lower in Beijing, Shanghai and Guangzhou (0.13, 0.07 and $0.05 \mathrm{~km}$ per sq.km.) than in overseas large cities such as Paris, New York and London (2.03, 0.54 and $0.29 \mathrm{~km}$ per sq.km.).

Urban rail transit volumes as share of total public transport still has a large room to grow. Even in large cities where urban rail transit was introduced years ago, such as Beijing, Shanghai and Guangzhou, the proportion of urban rail transit in total public transport volume is a mere $40 \%-50 \%$, significantly lower than $70 \%-80 \%$ in Paris and Tokyo. Nationwide, the ratio is only 14\%, indicating large upside. We expect urban rail transit transport volumes to maintain a $15 \%$ growth over the next 10 years, and its proportion of total public transport volume to reach $30 \%$.

Urban rail transit companies are generally loss-making in China, and their earnings model needs further improvement. Data from China Association of Metros shows that average operating cost and operating revenue of urban rail transit per unit passengerkilometers (PKM) stood at Rmb0.7 and Rmb0.5 in 2019, with average operating revenue to cost ratio falling from $78.0 \%$ in 2018 to $72.7 \%$. Overall, operation of urban rail transit is loss-making, and metro as a major type of urban rail transit is also reporting losses due to inefficiency of business diversification and operating mechanism.

China may look to the experience of Mass Transit Railway's (MTR) in Hong Kong for ways to optimize its subway operation mechanism. The overall intensity of MTR passenger transport (as measured by daily transport volume divided by operating length) is close to 23,000 passengers per km per day, $30 \%$ higher than the passenger transport intensity of metro in Guangzhou and more than three times the national average (7,000 passenger per km per day). MTR Corporation adopts the transit-oriented development (TOD) model, under which property developers obtain the land development rights at a relatively low cost, and the property projects create a new revenue source. In 2019, MTR Corporation recorded EBITDA of HK\$21bn (Fig. 10.5), with EBITDA margin reaching 38\% (well above the $19 \%$ at domestic peer Shentong Metro) where the station commercial services, property development, rental and management businesses each contributed 29\%, 27\% and 20\% of EBITDA. We think the Transit Oriented Development model (combination of metro and related property) will significantly enhance the operating efficiency of urban rail transit systems and reduce urban rail transit companies' reliance on government subsidies, creating a win-win for governments, the public, property developers as well as transit operators.

Issuance of real estate investment trusts (REITs) backed by urban rail transit assets offers a new solution for direct financing. We believe that REITs will serve as an effective supplement to the PPP model, and will help build a sustainable financing 


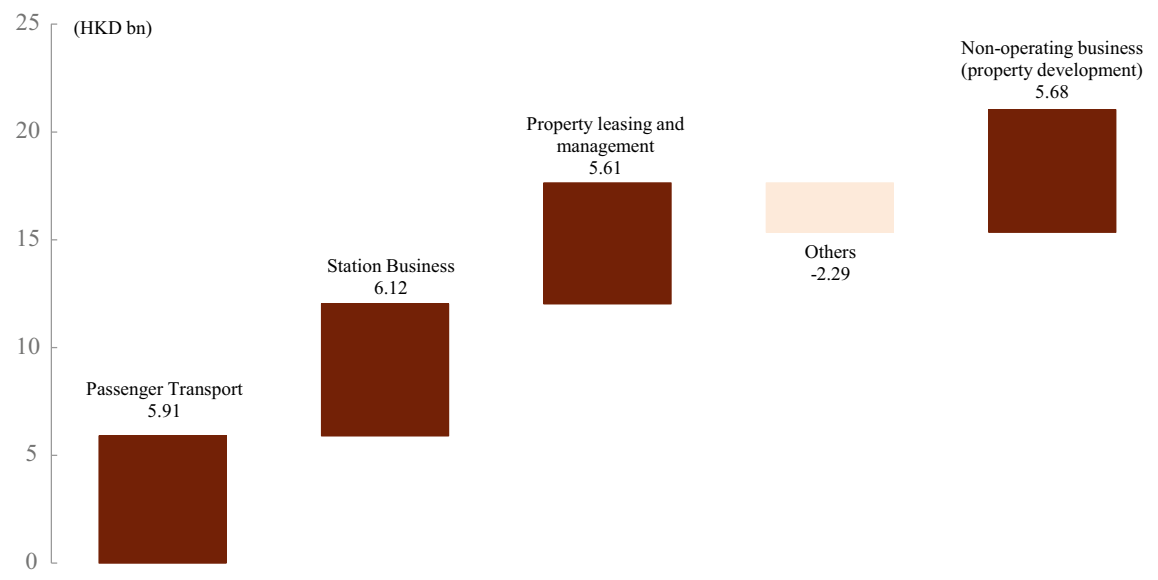

Fig. 10.5 Breakdown of MTR Corporation's EBITDA in 2019 (unit: HK\$100mn). Source MTR's announcement, CICC Research

system for urban rail transit. In addition, strict regulatory approval and information transparency are required to issue REITs in the urban rail transit industry. We believe closer supervision by regulators, the market and the public will force urban rail transit companies to improve operating efficiency, and diversify their business portfolio, thus improving sector profitability.

\subsubsection{Bike Sharing: A Solution for Last-Mile Travel}

As an environmentally friendly way of traveling, bike sharing could be a solution for the last mile from home and it would help reduce the traffic congestion and air pollution. The number of bike-sharing app users increased from $2.45 \mathrm{mn}$ in 2015 to $240 \mathrm{mn}$ in 2018 , a CAGR as high as $358 \%$, while fundraising volume in the bikesharing industry climbed from Rmb5.2bn in 2015 to Rmb83.3bn in 2017. With the bike-sharing industry being reshaped in 2018, investors became more prudent, and aggressive marketing campaigns were replaced by efficiency enhancement and quality improvement as the new focus for bike-sharing companies. The competitive landscape largely stabilized in 2019, with the three internet giant-backed bike-sharing firms (Hellobike, Meituan and Qingju) holding a combined market share of $95 \%$. We believe governments and bike-sharing companies should cooperate in addressing problems arising from the disorderly competition in past few years, such as excessive supply and unequal distribution of shared bikes, inefficient parking management, and hiding shared bikes for personal use.

We believe that governments should work more closely with bike-sharing companies to encourage shared bike supply, bike parking management, and business operation, in order to enhance the efficiency of bike-sharing services. Efficient management of shared bikes relies on the use of big data and the internet, and we thus believe 
governments and bike-sharing companies should collaborate in following aspects: (1) introducing a tender system for the increased supply of shared bikes; (2) jointly building the IT platform for data sharing; and (3) developing a credit system for the bike parking management. We believe closer cooperation between governments and bike-sharing companies will efficiently increase the active use of shared bikes, and reduce the vacancy rate.

\subsubsection{Jobs-Housing Balance Should Shorten Average Commuting Distance and Reduce Carbon Emissions}

Jobs-housing balance should markedly shorten commuting distance. As stated above, we estimate the total urban commuting distance will drop $83.7 \mathrm{bn} \mathrm{km}$ per year if residence and workplace are evenly distributed in 36 major cities. On the basis of this calculation, we estimate carbon emissions from commuting will decrease accordingly by $2.92 \mathrm{mnt}$ after considering the energy consumption and carbon emissions of different modes of transport (Table 10.1).

\subsection{Urban Construction: New Ideas, New Materials, and New Technologies Drive Reduction in Carbon Emissions}

This section discusses: (1) volume of carbon emissions from urban construction; (2) previous policies aimed at promoting energy conservation and emission reduction in the building sector; (3) possible reduction of carbon emissions from building sector by 2060 .

\subsubsection{Overview: Building Sector as a Whole Accounted for 36\% of National Carbon Emissions}

\subsubsection{Domestic Carbon Emissions from Building Sector Around 4.5bnt in 2019; to Drop $77 \%$ to $1.1 b n t$ in 2060}

Domestic carbon emissions from the building sector stood at around 4.5 bnt in 2019 , and pace of emission growth significantly slowed during the 13th five-year plan (FYP) period (2016-2020). Based on data from China Association of Building Energy Efficiency (CABEE), we estimate domestic carbon emissions from the entire building process reached 4.3bnt in 2018 and 4.52bnt in 2019, much higher than the global level. The carbon emission from urban construction also outpaced the population over 
Table 10.1 Estimated carbon emission reduction after residence and workplace are evenly distributed in 36 major cities

\begin{tabular}{|c|c|c|}
\hline \multicolumn{3}{|c|}{ Estimates of carbon emission saved by commuting distance } \\
\hline \multirow[t]{2}{*}{ Saved commuting distance (bn $\mathrm{km})$} & 83.7 & \\
\hline & $\begin{array}{l}\text { Proportion of } \\
\text { passenger } \\
\text { transportation } \\
\text { volume }\end{array}$ & Saved commuting distance (bn $\mathrm{km}$ ) \\
\hline Buses & $47 \%$ & 39.0 \\
\hline Urban rail transit & $16 \%$ & 13.5 \\
\hline $\begin{array}{l}\text { Passenger cars (including taxis and } \\
\text { ride-hailing cars) }\end{array}$ & $37 \%$ & 31.2 \\
\hline \multicolumn{2}{|l|}{ Buses } & \multirow[t]{10}{*}{ Total $\mathrm{CO}_{2}$ reduction: $2.92 \mathrm{mnt}$} \\
\hline Bus electrification rate & $59 \%$ & \\
\hline $\begin{array}{l}\text { Fuel consumption per } 100 \mathrm{~km} \text { of } \\
\text { diesel buses (L) }\end{array}$ & 30 & \\
\hline $\begin{array}{l}\text { Assumption of the number of people } \\
\text { carried by the bus }\end{array}$ & 20 & \\
\hline $\begin{array}{l}\text { Save carbon dioxide emissions by } \\
\text { buses (thousand tonnes) }\end{array}$ & 520 & \\
\hline \multicolumn{2}{|l|}{ Passenger cars } & \\
\hline Passenger car electrification rate & $3 \%$ & \\
\hline $\begin{array}{l}\text { Passenger car fuel consumption per } \\
100 \mathrm{~km}(\mathrm{~L})\end{array}$ & 6.8 & \\
\hline $\begin{array}{l}\text { Assumption of the number of } \\
\text { passengers carried by passenger car }\end{array}$ & 2 & \\
\hline $\begin{array}{l}\text { Save carbon emissions by passenger } \\
\text { cars (thousand tonnes) }\end{array}$ & 2,404 & \\
\hline
\end{tabular}

Source CICC Research

2008-2018 (76\% vs. 5\%) due to the large-scale urban construction. Domestic carbon emissions from building sector during the 11th, 12th and 13th FYP grew at a CAGR of $7.5 \%, 7.0 \%$ and $1.9 \%$, respectively. The marked slowdown of carbon emission growth during the 13th FYP indicates the effectiveness of energy conservation and emission reduction policies introduced during the period.

We expect carbon emissions from building sector to drop $32 \%$ and $77 \%$ in 2030 and 2060 compared with 2019. Energy consumption and carbon emissions of building sector mainly come from material production, building construction and building management (Table 10.2). Given that the building sector is a major source of carbon emissions, we believe energy conservation and emission reduction in the building sector is important for China and the rest of the world to achieve peak carbon emissions and carbon neutrality. The IEA estimates global carbon emissions from building sector should annually drop 6\% over 2020-2030 in order for the sector to achieve 
Table 10.2 Carbon emissions from building material production, construction, and building management

\begin{tabular}{|c|c|c|c|}
\hline & $\begin{array}{l}\text { Carbon emissions } \\
\text { from material } \\
\text { production }\end{array}$ & $\begin{array}{l}\text { Carbon emissions } \\
\text { from building } \\
\text { construction }\end{array}$ & $\begin{array}{l}\text { Carbon emissions } \\
\text { from building } \\
\text { management }\end{array}$ \\
\hline $\begin{array}{l}\text { Proportion of } \\
\text { energy } \\
\text { consumption } \\
(\mathbf{2 0 1 8 )}\end{array}$ & $51 \%$ & $2 \%$ & $47 \%$ \\
\hline $\begin{array}{l}\text { Proportion of } \\
\text { carbon emissions } \\
(\mathbf{2 0 1 8})\end{array}$ & $55 \%$ & $2 \%$ & $43 \%$ \\
\hline \multirow[t]{6}{*}{$\begin{array}{l}\text { Measures to save } \\
\text { energy and reduce } \\
\text { emissions }\end{array}$} & $\begin{array}{l}\text { Reduce emissions from } \\
\text { building material } \\
\text { production by: } \\
\text { upgrading production } \\
\text { technology, etc. }\end{array}$ & $\begin{array}{l}\text { Reduce building } \\
\text { construction by: } \\
\text { optimize urban } \\
\text { planning; prolonging } \\
\text { building service life, } \\
\text { etc. }\end{array}$ & $\begin{array}{l}\text { Promoting advanced } \\
\text { energy-conservation } \\
\text { buildings: such as } \\
\text { passive housing }\end{array}$ \\
\hline & \multirow{5}{*}{$\begin{array}{l}\text { Increase use of } \\
\text { eco-friendly materials: } \\
\text { such as light partition } \\
\text { wall material, etc. }\end{array}$} & \multirow{5}{*}{$\begin{array}{l}\text { Enhance construction } \\
\text { efficiency by: applying } \\
\text { digital technology to } \\
\text { building construction; } \\
\text { enhancing the } \\
\text { electrification of } \\
\text { construction } \\
\text { machinery, etc. }\end{array}$} & $\begin{array}{l}\text { Design: to enhance the } \\
\text { building energy } \\
\text { efficiency }\end{array}$ \\
\hline & & & $\begin{array}{l}\text { Building materials: } \\
\text { promote use of green } \\
\text { materials }\end{array}$ \\
\hline & & & $\begin{array}{l}\text { Building management: } \\
\text { Deploying smart } \\
\text { energy conservation } \\
\text { system }\end{array}$ \\
\hline & & & $\begin{array}{l}\text { Energy equipment and } \\
\text { energy supply system: } \\
\text { Optimize forms of } \\
\text { energy supply to } \\
\text { enhance energy } \\
\text { efficiency }\end{array}$ \\
\hline & & & $\begin{array}{l}\text { Renewable energy: } \\
\text { increase use of } \\
\text { renewable energy } \\
\text { sources such as solar } \\
\text { power and geothermal } \\
\text { power }\end{array}$ \\
\hline
\end{tabular}

Source China Association of Building Energy Efficiency, CICC Research

carbon neutrality in 2050. We expect carbon emissions from building sector to drop $32 \%$ and $77 \%$ compared with 2019 in 2030 and 2060 to 3.11 bnt and 1.05 bnt.

- Carbon emissions from building material production can be reduced by upgrading production technology, and the increased use of eco-friendly materials such as light partition wall materials. 
- Carbon emissions from construction can be reduced by prolonging building service life, applying digital technology (improving construction efficiency and reduce the production of construction waste), and enhancing the electrification of construction machinery.

- Carbon emissions from building management can be reduced by promoting advanced energy-conservation buildings such as passive houses, and developing full-process energy conservation solutions.

\subsubsection{Carbon Emissions from Construction: Reducing Overall Construction Volume and Enhancing Construction Efficiency}

\subsubsection{Production of Building Materials and Construction Both Generate Carbon Emissions, With the Majority Generated by Building Material Production}

Nearly $51 \%$ of carbon emissions from the building sector were generated by building material production and construction. Based on data from the China Association of Building Energy Efficiency, we estimate domestic carbon emissions from building material production and construction reached 2.09bnt and 100mnt in 2018, accounting for $49 \%$ and $2 \%$ of total emissions from the building sector.

- Carbon emissions from building material production: Cement, steel and aluminum are major materials used in construction, and production of these materials each accounted for $35 \%, 61 \%$, and $3 \%$ of total carbon emissions from building material production in China.

- Carbon emissions from construction: Emissions are largely due to energy consumption by construction machinery (such as excavator and power crane), as well as resource waste caused by the ineffective architectural design and the construction of temporary offices on construction sites.

Ways to reduce carbon emissions: Direct emissions reduction, and enhancement of construction efficiency. We think the new construction can be reduced by more reasonable urban planning and extension of building service life. Building demolitions and reconstructions are extensive in China. We believe reasonable and scientific urban planning can avoid unnecessary new construction, and the building service life can be prolonged by building quality improvements. In addition, the increased use of eco-friendly building materials and construction technologies will decrease carbon emissions per unit GFA. 


\subsubsection{Direct Emission Reduction: Improved Urban Planning and Extension of Building Service Life}

Optimizing urban planning to avoid unnecessary demolition and reconstruction. Demand-based urban planning can avoid unnecessary new construction and reduce carbon emissions from building demolition.

Improving building quality to prolong building service life. Short building service life will lead to more new construction per year. The average service life of buildings constructed in the early stage of urbanization is less than 50 years in China, suggesting significant upside compared to an average of 132 years in the UK and 74 years in the US.

Using recyclable building materials. Unlike existing buildings made by reinforced concrete, the steel structure buildings are more recyclable, flexible, earthquakeresistant, and produce less construction waste. In addition, the steel used in the steel structure buildings can be recycled after buildings are dismantled. We expect the penetration rate of steel structure buildings to rise from current around $10 \%$ to $60 \%$ in 2060 .

\subsubsection{Improving Construction Efficiency \#1: Reducing Carbon Emissions from Building Material Production}

Cement: Technological upgrades can reduce unit consumption of coal and electric power during cement production. Our estimate of $\mathrm{CO}_{2}$ emissions from producing one tonne of cement was 0.59 tonnes in 2019. Due to technological upgrades and increased the use of clean energy sources, it will likely drop to 0.57 tonnes in 2025 , 0.55 tonnes in 2030, and 0.40tonnes in 2060.

Steel: Switch from blast furnace to electric arc furnace (EAF). Our estimate of $\mathrm{CO}_{2}$ emissions from producing one tonne steel was 1.52tonnes in 2019 and it will likely drop to 1.33 tonnes in 2025, 1.10tonnes in 2030, and 0.50tonnes in 2060.

Aluminum: Increased use of power generated from clean energy sources. Our estimate of $\mathrm{CO}_{2}$ emissions from producing one tonne of aluminum was 7.37 tonnes in 2019 and it will likely drop to 6.91tonnes in 2025, 5.80tonnes in 2030, and 1.76tonnes in 2060 .

New materials: Replacement of bricks and tiles with light partition walls. We estimate the application of light partition walls will reduce carbon emissions per unit GFA by $53 \mathrm{~kg}$.

\subsubsection{Improving Construction Efficiency \#2: Reducing Carbon Emissions from the Construction Process}

Industrialized construction. Penetration rate of prefabricated buildings remained as low as $13.4 \%$ in 2019 and we expect it to increase gradually. This, coupled with 
economies of scale, should reduce energy consumption and carbon emissions of buildings.

Digital technologies such as building information modeling (BIM) to reduce extra carbon emissions and building waste caused by reconstruction. Reconstruction often occurs due to inefficient communication between building designers and construction companies. We believe digital technologies such as BIM can detect flaws in the engineering design before construction starts, and this will help reduce waste and carbon emissions caused by reconstruction.

Electrification of construction machinery such as excavators. Only a small portion of existing construction machinery in China is electric, and most are small or micro excavators used in small construction projects. The large-scale adoption of electric excavators is hindered by the insufficient energy storage (insufficient for excavators' high power draw) and the difficulty of setting up connection cables on construction sites. We believe advances in battery energy storage technology and the promotion of industrialized construction, which helps tidy up construction sites, may help increase the use of electric construction machinery.

\subsubsection{Carbon Emission from Building Management: Passive House Technology and Comprehensive Energy Conservation Solutions to Reduce Carbon Emissions from Building Management}

\subsubsection{Passive Houses (Ultra-Low Energy Buildings): Improving Thermal Insulation of Buildings to Save Energy}

Passive houses (ultra-low energy buildings): High-standard insulation to reduce energy consumption, especially in cold regions. Passive house is a standard for energy efficiency in a building and its requirement for high-level heat insulation and air impermeability can minimize heat loss and active fossil fuel consumption. ${ }^{1}$ We believe it is a reasonable solution to saving energy consumption by buildings in cold regions.

Promoting ultra-low energy buildings started in China during the 13th FYP and we expect a pick-up in the adoption of such buildings in northern China. China introduced the advanced passive house technology from abroad a few decades ago and gradually adapted it to domestic conditions. The demonstrative passive house projects were launched during the 13th FYP.

\footnotetext{
${ }^{1}$ The definitionincluded in European standards, technologies and practices for ultra-low energy buildings and passive buildings announced by MoHURD in 2011.
} 


\subsubsection{Comprehensive Energy Conservation Solutions for the Entire Construction Process}

We believe coordinated efforts are needed for China's building sector to achieve its carbon emissions reduction target in 2060, and possible solutions include: (1) reducing building energy consumption by optimizing architectural design, increasing the use of eco-friendly building materials, and installing smart building management systems; and (2) reducing per unit energy consumption by optimizing energy systems such as heating, cooling, household hot water supply, and heat for cooking as well as promoting the use of renewable energy sources such as solar power, geothermal power, and PV.

Architectural design: Introducing Passive House-alike standards to enhance energy savings. The Ministry of Housing and Urban-Rural Development (MoHURD) issued several standards for conserving energy in buildings in the past few years to promote the concept of Passive House. Only some requirements are mandatory and we think full adoption of energy conservation standards will enhance the building energy efficiency.

Building materials: Promoting use of green building materials such as energyefficient glass, and thermal insulation materials. The CICC Building Materials team expects the introduction of higher standards for building energy efficiency will boost demand for energy-efficiency glass, heat insulation materials, and lightweight materials.

Building management: Deploying smart energy conservation system for more efficient operation of energy systems and equipment.

Energy equipment and energy supply system: Optimizing forms of energy supply to reduce waste and enhance energy efficiency. The heating and ventilation facilities inside a building consume energy and produce carbon emissions. Assuming demand for energy consumption in buildings remains unchanged, we believe carbon emissions per unit energy consumption can be reduced by replacing central heating with flexible heating and using heating appliances that are more efficient.

Renewable energy: Increasing the use of renewable energy sources such as solar power and geothermal power. Data from the MoHURD shows that the penetration rate of renewable energy among civic buildings exceeded $4 \%$ at end-2015, and will likely reach $6 \%$ in $2020 .^{2}$

\subsubsection{Carbon Emissions from Building Management to Drop 79\% to 450mnt Over 2019-2060}

We expect domestic carbon emissions from building management to reach $1.49 \mathrm{bnt}$ in 2030 and 450mnt in 2060, down $31 \%$ and $79 \%$ compared with 2019 . We believe factors affecting carbon emissions from building management include population,

\footnotetext{
${ }^{2}$ A target set by the MoHURD in the 13th FYP for conserving energy in buildings issued in March 2017.
} 

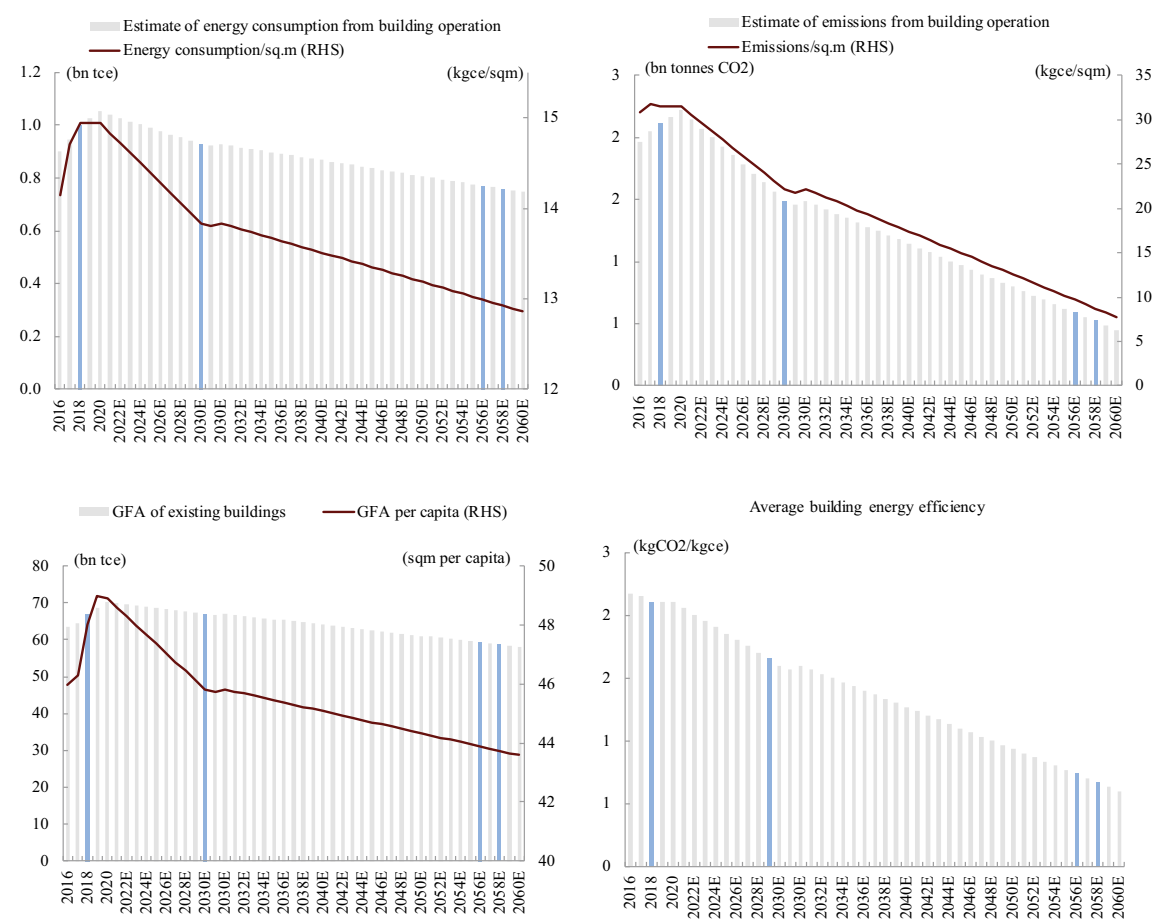

Fig. 10.6 Energy consumption and carbon emissions in domestic building sector will likely drop markedly in 2030 and 2060. Source National Bureau of Statistics, China Building Energy Consumption Research Report by China Association of Building Energy Efficiency, CICC Research

building GFA per capita, energy consumption per unit GFA (energy consumption intensity) and carbon emissions per unit energy consumption (energy efficiency). Specifically, we believe energy efficiency enhancement is a major driver of carbon emission reduction in building management (Fig. 10.6).

- Population: Slower growth from 2020 onwards. Data from National Bureau of Statistics shows that national population stood at $1.4 \mathrm{bn}$ in 2019. Based on data from United Nations, we expect population growth to gradually slow over 20202030, and total population start to decline from 2034 onwards. Based on our forecast, the national population will reach 1.46bn in 2030 and 1.33bn in 2060.

- Building GFA per capita: Expect continued declines from 2020 onwards. We estimate that domestic building GFA per capita is 49.0 sqm in 2019, including $15.7 \mathrm{sqm}$ of public buildings, $36.8 \mathrm{sqm}$ of urban residential housing, and $43.7 \mathrm{sqm}$ of rural residential housing. We expect GFA per capita of public buildings, urban residential housing, and rural residential housing to drop to $13.3 \mathrm{sqm}, 31.3 \mathrm{sqm}$ and $36.8 \mathrm{sqm}$ in 2060 , respectively. 
- Energy consumption intensity: We expect average energy consumption intensity to drop for building renovations, accompanied by a higher proportion of lowenergy buildings. We estimate that national average building energy consumption reached $14.9 \mathrm{kgce} / \mathrm{sqm}$ in 2019 and it will likely decline to $12.0 \mathrm{kgce} / \mathrm{sqm}$ in 2060 . We assume: (1) the proportion of near-zero ultra-low-energy buildings in existing building GFA will reach 3\% in 2060; and (2) the energy conservation solutions along the value chain will help reduce energy consumption intensities of normal buildings. Based on these assumptions, we estimate average energy consumption intensity of buildings will drop to $12.9 \mathrm{kgce} / \mathrm{sqm}$ in 2060 .

- Energy efficiency: We expect energy efficiency to markedly decline driven by lower proportion of non-fossil energy in primary energy consumption. Our estimate shows that national average building energy efficiency is $2.1 \mathrm{~kg} \mathrm{CO}_{2} / \mathrm{kgce}$ in 2019 and coal accounted for $76 \%$ of primary energy consumption (of which $50 \%$ was used for power generation, $30 \%$ for heat generation, and $20 \%$ as fossil fuels). In 2060, we expect national average building energy efficiency to drop to $0.6 \mathrm{~kg} \mathrm{CO} / \mathrm{kgce}$, assuming: (1) the proportion of coal used for heat generation and as fossil fuels will fall to 5\%; and (2) the proportion of fossil energy in primary energy consumption for power generation will drop to $10 \%$.

\subsection{Urban Maintenance: Reduce Energy Consumption by Public Service Facilities, and Improve Resource Recycling Efficiency}

This section discusses potential reduction of carbon emissions from urban maintenance and the importance of improving the efficiency of urban maintenance and resource recycling. We believe energy conservation and adopting digital technologies are the key to reducing carbon emissions from public utilities such as water and heating supply. We also believe that introducing supportive policies will help reduce carbon emissions from facilities for water and heat supply and provide plenty growth potential for resource recycling.

With the economic development, the desire for a higher standard of living has driven up energy consumption for urban maintenance and operations. For example, the Building Energy Research Centre of Tsinghua University estimates that energy consumption for urban heating in northern China reached $212 \mathrm{mnt}$ of standard coal in 2018, producing around 550mnt of carbon emissions (around 25\% of total emissions from the building sector). We believe improving urban maintenance efficiency and lowering unit energy consumption hold the key to reducing carbon emissions from urban maintenance. Carbon neutrality can be achieved through these two aspects.

- Improving urban maintenance efficiency. Public utilities such as heat and water supply are generally a necessity for urban residents, and the continued urban construction will gradually boost demand for such facilities. The lack of new 
infrastructure facilities and the aging of existing facilities have led to low efficiency of urban maintenance. We believe energy use by urban infrastructure can be optimized by renovating existing infrastructure and improving supply efficiency.

- Improving resource recycling efficiency. The rapid urban development has substantially increased resource demand. We believe that the recycling of renewable resources is less energy-consuming than direct resource production which is aligns with the green city strategy. We see large upside in the domestic recycling rate.

\subsubsection{Conserving Energy and Reducing Emissions by Using Technology to Reduce Carbon Emissions from Public Utilities}

\subsubsection{Water Supply: Using Digital Water Supply Management to Enhance Water Use Efficiency}

Energy consumption for urban water supply: Water supply volume per resident has gradually increased in China, while stable urban water supply is of vital importance. Water supply companies need energy sources, mostly electrical power, to adjust hydraulic pressure and flow speed. Based on the current output of water supply firms in cities, our estimate shows that power consumption for urban water supply had reached $19.12 \mathrm{bn} \mathrm{kWh}$ in 2019.

Possible measures to reduce carbon emissions from water supply: The low quality and inefficient management of water supply pipes built in the early stage of urban development have led to a water loss as high as $14 \%$ in 2019 according to MoHURD. We believe energy consumption for water supply can be reduced by using water more efficiently, raising awareness about water conservation among residents, and applying digital technology in water supply management.

- Reducing water loss: The National Water Pollution Control Action Plan stresses that renovating 50-year-old or older water supply pipes will improve the overall stability of water supply and reduce water loss. In addition, the digitalization of water management system can locate the water loss by monitoring water supply pipes, and eventually avoid water loss.

- Adopting smart water supply system: We believe technologies such as artificial intelligence, big data, and internet of things (IoT) will help water supply companies reduce unit power consumption. 


\subsubsection{Heat Supply: Promoting Central Heating to Improve Heating Efficiency in the Near Term; Transforming the Energy Mix over the Long Term}

Central heating has been available in Northern China since the 1950s. The QinlingHuaihe Line is a reference line used by geographers to distinguish between northern and southern China, corresponding roughly to the 33rd parallel. Central heating helps maintain the basic living condition for general public and the functioning of cities' utilities.

Promoting central heating has been faster in urban than in rural regions. Areas covered by central heating in cities and counties grew from $1.1 \mathrm{bn}$ sqm and $70 \mathrm{mn}$ sqm in the early 21 st century to 9.25 bn and 1.75 bn sqm in 2019 , a CAGR of $9 \%$ and $12 \%$. According to the China Clean Energy Development Report (2020) by China Institute of Energy economics research, the central heating system covered $14.1 \mathrm{bn}$ sqm of northern cities and counties $(78 \%)$ and $7 \mathrm{bn}$ sqm of northern rural regions (nearly 6\%) as of 2019 .

Central heating offers higher thermal efficiency than individual heating while coal remains a major heat source. According to China Heat Supply Industry Development Report (2020), ${ }^{3} 45 \%$ of central heating in northern cities and counties came from coal-fired cogeneration, $27 \%$ from coal-fired boilers, $3 \%$ from gas-fired cogeneration, $10 \%$ from gas-fired boilers, and $7 \%$ from gas-fired wall-mounted heaters. Overall, coal and gas were the heat sources for nearly $72 \%$ and $20 \%$ of central heating. According to Discussions on How to Improve Thermal Efficiency of Central Heating, thermal efficiency is around $85 \%$ for cogeneration, $80 \%-90 \%$ for large heating boilers, $30 \%-50 \%$ for individual coal-fired boilers, $55 \%-65 \%$ for coal-fired boilers that complete energy conservation renovation, and 75\%-80\% for gas-fired boilers. We believe the central heating system can help reduce the energy consumption per unit heating area.

Carbon emissions in the heating supply sector are to be reduced by enhancing thermal efficiency in the near term and by transforming energy consumption mix in the long term. Household heating demand may continue to grow, thus, coordinated efforts along the value chain are needed in order to reduce carbon emission from urban heating. Cities can reduce emissions by: (1) reducing overall energy demand while satisfying residents' heating demand, via measures such as enhancing heating efficiency and adopting energy-saving building materials or smart building systems, and (2) improving the energy consumption mix by increasing the use of renewable energy.

\footnotetext{
${ }^{3}$ The report issued by China Urban Heating Association in August 2020.
} 


\subsubsection{Ample Downside in Carbon Emissions from Water and Heat Supply}

Carbon neutrality and environmental protection will be long-term policy directions. 2021 marks the first year of the 14th FYP period, and we expect the government to continue promulgating policies that enhance water efficiency and promote clean heating.

- Water supply: The National Water Pollution Control Action Plan requires that water loss rate of national water supply pipes should fall below $10 \%$ in 2020 . Given the renovation of old water pipes and the application of digital technology, we expect water loss will decline to $5 \%$ in 2030 . In addition, we believe unit water consumption for both household and industrial uses will decrease on the construction of water-efficient cities. We expect unit water consumption to fall $5 \%$ in 2030 compared with 2020 and further decline in future. We think the digital technology will enhance the water supply efficiency and further reduce the unit energy consumption for water supply. We expect unit energy consumption for water supply will decline 5\% over the 14th and 15th FYP periods.

- Heat supply: We expect the penetration rate of central heating to rise from $54 \%$ in 2020 to $75 \%$ in 2030 (including in rural regions) and the proportion of heat generated from coal burning to drop to $50 \%$.

\subsubsection{Resource Recycling to Help Build Low-Carbon Cities}

\subsubsection{Resource Recycling to Reduce Carbon Emissions}

Domestic demand for resources keeps rising. The Chinese economy has maintained rapid growth since its opening-up which, coupled with industrialization and higher standards of living, has led to growing demand for resources. Chinese industrial added value increased at a CAGR of $10.8 \%$ since the start of the twenty-first century with the growth rate slowing from over $15 \%$ over $2000-2010$ to $5.4 \%$ over $2011-$ 2020. In addition, consumption per urban resident and per rural resident increased at a CAGR of $8.7 \%$ and $11.1 \%$ since the start-twenty-first century and maintained high growth on the whole despite mild declines in 2020 due to the pandemic.

Demand for all types of resources rising rapidly; resource recycling may help reduce urban carbon emissions. Rising gross industrial output and consumption levels boost China's resource demand. In 2019, China represented around 51\%, 15\%, and $40 \%$ of global consumption demand for steel, plastic and rubber. Since the production of industrial and consumer goods requires energy, we think the recycling of waste resources (i.e., steel, rubber and plastic) will ease the rising demand pressure and lower energy consumption in production, contributing to the goal of carbon neutrality.

- Scrap steel recycling: Overseas experience shows that the proportion of electric arc furnace (EAF) process in total output will rise when crude steel output reaches a 

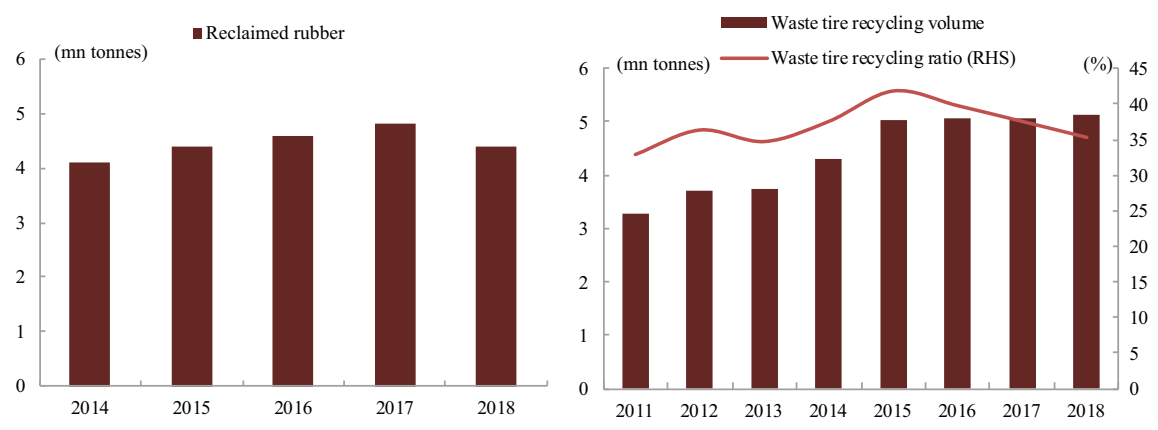

Fig. 10.7 Recycling volume of rubber and waste tires. Source Ministry of Commerce, China Rubber Industry Association, CICC Research

certain level. In 2018, EAF process only contributed $10 \%$ output, much lower than global market's 35\%. According to the Transformation and Upgrade Plan for the Iron and Steel Industry released by the Ministry of Industry and Information Technology, China aims to raise the proportion of scrap steel in steelmaking to $30 \%$, pointing to large growth potential. Compared with iron ore-based steelmaking, EAF process lowers energy consumption by $76 \%$.

- Waste rubber recycling: Based on R\&D data of relevant companies, we estimate that waste rubber recycling lowers renewable energy consumption by $30 \%$. Recycling reduces waste rubber's harm to the environment. Data from China Rubber Industry Association shows that China produced 14.8mnt waste tires in 2019 with a CAGR of 5\% over 2011-2019, pointing to ample waste tire resources. However, only 5.12mnt (35.3\%) waste tires were recycled in 2018, far less than the 8.5mnt/year target for 2020 (set in the Guideline for Green Manufacturing 2016-2020) (Fig. 10.7).

- Plastic waste recycling: As a large plastic producer and consumer, China keeps improving its plastic recycling system. According to INTCO's prospectus, 38\% of plastic waste was recycled in 2018. Data from Shanghai Resource Recycling Trade Association shows that China recycled around 30\% plastic waste in 2019. According to a study published on the Science of The Total Environment by the University of Manchester, the recycling of one tonne of plastic lowers 2.3tonnes of carbon emission. The world is also stepping up efforts in plastic waste recycling. The EU plans to raise its plastic-waste recycling rate to $50 \%$ in 2025 and $55 \%$ by 2030. Japan aims at a 100\% effective utilization of used plastic (including thermal recovery) in 2035. The US also announced its plan to achieve $100 \%$ recycling \& reuse of plastic packaging in 2040.

Lithium-ion battery $(\mathrm{LiB})$ recycling: Given efforts toward carbon neutrality, we believe alternative fuel vehicle will replace traditional vehicles and LiB demand will continue to surge, boosting demand for relevant raw materials (i.e., metals). Some elements will be reused in the new LiB production, lowering demand for the mining of raw materials and carbon emissions. 


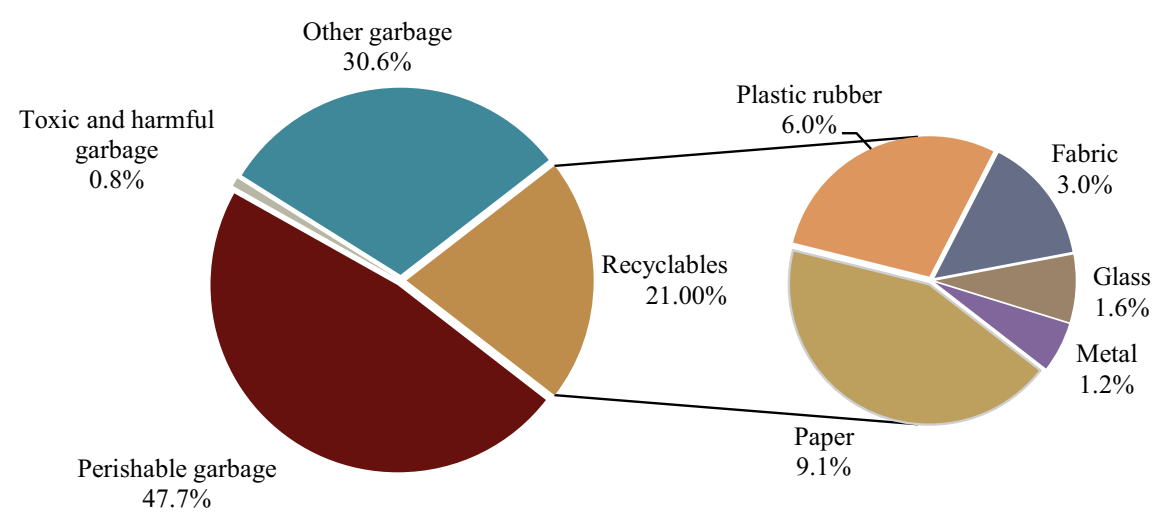

Fig. 10.8 Recyclable waste accounts for a high proportion in household waste. Note Data as of 2018. Source Data from Sound Group, CICC Research

\subsubsection{Expecting Policy Support to Accelerate Recycling of Renewable Resources}

Various recyclable materials are present in waste material. Households and industrial production produce considerable waste. China's waste volume is rising amid rapid economic growth. However, waste is not useless and contains a range of recyclable materials. Data from Sound Group shows that recyclable waste (i.e., paper, plastic, glass and scrap metal) accounted for around 20\% of household waste in 2018 (Fig. 10.8).

Waste sorting lays a foundation for resource recycling. Waste sorting is the first step in resource recycling. We attribute the slow growth of renewable resource recycling in China to underdeveloped recycling systems, the extensive market expansion, and the country's reliance on low-efficiency waste pickers who collect renewable waste from the streets. We believe the construction of waste sorting system sets an industry-wide standard and will boost the recycling rate of renewable resources. The government has issued supporting policies such as "zero waste city" and "waste sorting" since 2019, promoting recycling and reuse of renewable resources.

Implementation of waste sorting policies. The Ministry of Housing and UrbanRural Development and other eight ministries jointly announced the application of household waste sorting in prefecture- or higher-level cities on June 11, 2019. It stated that 46 major cities should complete the waste sorting and disposal system by the end of 2020 and other cities should complete the system in 2025. In November 2020, the Ministry of Housing and Urban-Rural Development and other 11 departments announced measures to promote household waste sorting, aiming to further reduce household waste volume, achieve harmless treatment, and turn waste into power. They plan to enact relevant laws and regulations and continue to raise China's household waste recycling rate to over $35 \%$ within five years. 
Open Access This chapter is licensed under the terms of the Creative Commons AttributionNonCommercial-NoDerivatives 4.0 International License (http://creativecommons.org/licenses/bync-nd/4.0/), which permits any noncommercial use, sharing, distribution and reproduction in any medium or format, as long as you give appropriate credit to the original author(s) and the source, provide a link to the Creative Commons license and indicate if you modified the licensed material. You do not have permission under this license to share adapted material derived from this chapter or parts of it.

The images or other third party material in this chapter are included in the chapter's Creative Commons license, unless indicated otherwise in a credit line to the material. If material is not included in the chapter's Creative Commons license and your intended use is not permitted by statutory regulation or exceeds the permitted use, you will need to obtain permission directly from the copyright holder.

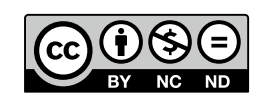

